\title{
Parents' dietary patterns are significantly correlated: findings from the Melbourne Infant Feeding Activity and Nutrition Trial Program
}

\author{
Sandrine Lioret*, Sarah A. McNaughton, David Crawford, Alison C. Spence, Kylie Hesketh \\ and Karen J. Campbell \\ Centre for Physical Activity and Nutrition Research (C-PAN), School of Exercise and Nutrition Sciences, Deakin University, \\ 221 Burwood Highway, Burwood, VIC 3125, Australia
}

(Submitted 29 March 2011 - Final revision received 30 August 2011 - Accepted 23 September 2011 - First published online 1 November 2011)

\begin{abstract}
The objectives of the present study were to identify dietary patterns independently in first-time mothers and fathers, and to examine whether these patterns were correlated within families. Dietary intakes were collected at baseline in the Melbourne Infant Feeding Activity and Nutrition Trial Program using a validated FFQ in 454 pairs of first-time mothers and fathers. Education level was reported in associated questionnaires. Principal components analyses included frequencies of fifty-five food groups and were performed independently in mothers and fathers. Spearman's correlation coefficients were used to assess associations between dietary pattern scores. A total of four dietary patterns were identified in mothers and fathers. Of these, three dietary patterns had similar characteristics between these two populations, namely 'Fruits and vegetables', 'High-energy snack and processed foods', 'High-fat foods' in mothers; and 'Fruits', 'High-energy snack and processed foods', 'High-fat foods' in fathers. The following two additional patterns were identified: 'Cereals and sweet foods' in mothers and 'Potatoes and vegetables' in fathers. Patterns incorporating healthier food items were found to be positively associated with parent education. An inverse association with education was found for the 'High-fat foods' and 'High-energy snack and processed foods' dietary patterns. Qualitatively similar patterns between corresponding mothers and fathers were the most strongly correlated ( $\rho=0.34-0.45, P<0 \cdot 001)$. There were some differences in dietary patterns between mothers and fathers, suggesting that it is worth deriving patterns separately when considering couples, and more generally between men and women. Exploring how these various patterns correlate within households provides important insights to guide the development and implementation of family-based interventions.
\end{abstract}

Key words: Dietary patterns: Mothers: Fathers: Correlations: Factor analysis

The rapid increase in obesity prevalence among children and adults over the last three decades primarily suggests the role of behavioural factors, which are influenced by social and economic environments. Unhealthy eating behaviours, low physical activity and increased sedentary behaviours have often been implicated, but their exact contribution to energy imbalance remains contentious. In their Ecological Systems Theory approach, Davison \& $\operatorname{Birch}^{(1)}$ have highlighted the importance of considering the context in which a person is located when studying the determinants of obesity. The family environment, which is the first ecological niche of children, has been hypothesised to play a crucial role, as this is where parents model eating and activity behaviours.

Evidence indeed suggests that parents have a strong influence on the development and maintenance of their children's eating behaviours and that this begins in infancy ${ }^{(2,3)}$. Parents are notably responsible for the foods available at home and the way in which foods are prepared and shared within the family ${ }^{(4,5)}$. Further research is, however, warranted to better describe the way these behaviours aggregate within households. It is also of interest to consider the congruence between parents' dietary intakes, as this may provide important insights into the ways in which interventions targeting home environments may need to be developed.

The statistical methods used to assess the overall diet include a posteriori approaches, such as cluster and factor analyses, and the a priori dietary index approach ${ }^{(6)}$. These methods have been developed in nutritional epidemiology to overcome the inability of the traditional single-nutrient or single-food approaches to account for collinearity among dietary components. In fact, although single-nutrient and singlefood studies are valuable, they do not accurately represent the complexity of the diet. Principal components analysis (PCA) has therefore been used to identify and assess overall

Abbreviations: InFANT, Infant Feeding Activity and Nutrition Trial; PCA, principal components analysis.

*Corresponding author: Dr S. Lioret, fax +61392446017, email sandrine.lioretsuteau@deakin.edu.au 
food patterns of a given population. PCA is a multivariate method that allows the potential effect of the interactions within combinations of foods and nutrients to be taken into account. Based on this methodology, dietary patterns have been shown to vary according to age and socio-economic status $^{(6)}$. Differences in dietary patterns between men and women have also been investigated. Most existing studies have derived patterns for men and women combined and then compared the resulting scores by sex, usually reporting non-significant differences ${ }^{(6)}$. Others have focused on populations of women more specifically ${ }^{(7-10)}$. Rarer are the studies that have considered men and women separately ${ }^{(11,12)}$, and even less attention has been given to dietary patterns within families. A recent study conducted with young Australian women ${ }^{(13)}$ has suggested that the diet quality of young mothers is similar to that of young women in general. Less is known about the eating behaviours in men in the context of family life ${ }^{(14)}$. Northstone \& Emmet ${ }^{(15)}$ have recently shown that although men and women in marriage-like partnerships displayed similar dietary patterns, differences in food groups were observed.

In this context, the present study aimed to identify dietary patterns independently in first-time mothers and fathers, using the cross-sectional baseline data of the Melbourne Infant Feeding Activity and Nutrition Trial (InFANT) Program. A second objective was to examine whether these patterns were correlated within couples.

\section{Materials and methods \\ Participants and study design}

The Melbourne InFANT Program is a cluster-randomised controlled trial, which has been described in detail elsewhere $^{(16,17)}$. The intervention involved first-time mothers from when their infants were $3-18$ months of age, which is a stage of transition to motherhood when women are likely to be more receptive to nutrition advice. The study was conducted within Greater Melbourne, Victoria, Australia across all socio-economic position areas. Baseline data were collected from June to December 2008. Briefly, a two-stage random sampling design was used to include primary carers attending first-time parent groups, which are coordinated through Maternal and Child Health Centers across Victoria. Inclusion criteria were literacy in English and a minimum of eight parents (six in low-socio-economic position area groups) in the groups consenting to take part. Of the eligible parents, $86 \%$ ( $n$ 542) consented to participate in the Melbourne InFANT Program. The present analysis excluded non-firsttime mothers ( $n$ 14), single-parent families ( $n$ 8), one couple where the father was the main carer, another couple composed of two women, and sixty-four couples with incomplete FFQ in mothers ( $n$ 19) and/or fathers ( $n$ 62). Therefore, the final sample was 454 pairs of first-time mothers and fathers.

The Melbourne InFANT Program was approved by the Deakin University Human Research Ethics Committee and the Victorian Government Department of Human Services, Office for Children, Research Coordinating Committee.

\section{Measurements}

Data were collected using self-administered questionnaires provided to mothers and fathers at baseline. Questionnaires were returned and checked by research staff at the first of the Melbourne InFANT Program sessions or returned by mail with follow-up by phone if necessary.

Demographic and socio-economic data included parents' and children's dates of birth, marital status, country of birth, main language spoken at home, employment status and education level. Education level was defined in three categories: low (secondary school or below), intermediate (trade and certificate qualifications) or high (university degree or higher). Duration of pregnancy, breast-feeding status at baseline, weight and height before pregnancy in mothers, and weight and height at baseline in fathers were also reported. BMI was calculated as weight $/$ height $^{2}\left(\mathrm{~kg} / \mathrm{m}^{2}\right)$.

Parental dietary intake was collected using the validated Cancer Council Victoria FFQ (version 3), which is an updated version of the semi-quantitative FFQ specifically developed for the Melbourne Collaborative Cohort Study ${ }^{(18)}$. Parents were asked to indicate how often they had consumed each food or beverage item over the preceding 12 months. The FFQ has ten response options for ninety-eight food items ranging from 'never' to 'three or more times per day'. These data were converted into daily equivalent frequencies according the Cancer Council Victoria protocol. The FFQ also included eleven additional questions relating to the type and amount of milk consumed (number of glasses per d); the amount of diet and non-diet soft drinks consumed (number of glasses per $\mathrm{d}$ ); the type and amount of bread consumed (number of slices per d); the number of eggs per week; and the frequency per week of both alcoholic and hot beverages. Of the participants, nineteen mothers and thirty fathers had partially completed FFQ, but as the corresponding missing data corresponded to $<5 \%$ of the questions, the missing values were imputed as zeros and the corresponding subjects included in the analyses, as is standard practice in nutritional epidemiology ${ }^{(19)}$. Based on the assessment of the similarities in food type, energy density and context of consumption, all foods and beverages were assembled into fiftyfive groups (Table 2) and frequencies of foods within each group were summed. As different units were used throughout the questionnaire, all dietary data were standardised by subtracting the mean and dividing by the standard deviation within each of these food groups.

\section{Statistical analyses}

Dietary patterns were derived independently in mothers and fathers using PCA with varimax rotation of the fifty-five food groups $^{(20)}$. The number of patterns was selected considering eigenvalues $>1 \cdot 0$, the scree plot and the interpretability of the patterns ${ }^{(21)}$. To interpret the results, we considered the items most strongly related to the pattern, i.e. those for which the loading coefficient was $>\|0 \cdot 20\|$ (which represent the correlations of each variable with one given dietary pattern). Dietary pattern labels were allocated according to the 
most significant items associated with the dietary pattern. The factor score for each dietary pattern was calculated at the individual level by summing the observed standardised frequencies of consumption per food group weighted according to the factor loadings.

For a given dietary pattern, multivariable regression analysis was performed to investigate the relationships between the pattern score (as the outcome) and two classical covariates of food intake: age (continuous) and education level (categorical). Clustering by first-time parent group was accounted for in all models. Adjusted parameter estimates and 95\% CI were calculated. Spearman's correlation coefficients were then used to assess the associations between the pattern scores of mothers and fathers.

The accepted significance level was set at 5\%. Analyses were computed using Stata software (release 10; StataCorp LP, College Station, TX, USA).

\section{Results}

\section{Sample characteristics}

Demographic and socio-economic characteristics of the 454 first-time mothers and 454 fathers included in the present study are shown in Table 1 . Mothers had an average age of 32.3 years. Approximately $75 \%$ of them were breast-feeding their baby at baseline. A majority (55.5\%) had achieved a university education level (high education level), 25.3\% trade and certificate qualifications (intermediate education level) and $19 \cdot 2 \%$ secondary school or below (low education level). Fathers were aged $34 \cdot 2$ years on average. About $40 \%$ had achieved a high education level, 33.1\% an intermediate education level and $26.7 \%$ a low education level. Nearly all of them were employed (97.3\%). Overall, more than threequarters of mothers and fathers were born in Australia.

It should be noted that the sixty-four mothers excluded from the analyses due to incomplete FFQ data in mothers and/or fathers did not differ significantly from those retained in terms of age or education level (data not shown).

\section{Characteristics of dietary patterns}

A total of four dietary patterns were identified in mothers, accounting for $24.1 \%$ of the explained variance (Table 2). The first pattern was positively correlated with the consumption of fruits and vegetables, non-fried fish, salad dressing, nuts other than peanuts, and herbal tea. This pattern was labelled 'Fruits and vegetables'. The second pattern, labelled 'High-energy snack and processed foods', was mainly characterised by high consumption of processed foods, such as savoury pastries, pizzas, crisps, chocolate products, peanut products, yeast extracts/spreads and ketchup. The third pattern had high positive loadings for full-cream milk, white bread, fried fish, potatoes cooked with added fat, cakes and pastries, fat spreads, and fat added to vegetables. This pattern was named 'High-fat foods'. The fourth pattern was a mixed pattern with high loadings for cereals (wholemeal crackers; breakfast cereals), reduced-fat milk and sweets (ice cream;
Table 1. Characteristics of the sample

(Mean values, standard deviations, percentages and $95 \%$ confidence intervals)

\begin{tabular}{|c|c|c|c|c|}
\hline & \multicolumn{2}{|c|}{ Mothers } & \multicolumn{2}{|c|}{ Fathers } \\
\hline & $\%$ & $95 \% \mathrm{Cl}$ & $\%$ & $95 \% \mathrm{Cl}$ \\
\hline$n$ & & 454 & & 454 \\
\hline \multicolumn{5}{|l|}{ Age (years) } \\
\hline Mean & & $32 \cdot 3$ & & $34 \cdot 2$ \\
\hline $\mathrm{SD}$ & & $4 \cdot 2$ & & 4.9 \\
\hline \multicolumn{5}{|l|}{ BMI $\left(\mathrm{kg} / \mathrm{m}^{2}\right)$} \\
\hline Mean & & $24 \cdot 4$ & & $27 \cdot 8$ \\
\hline SD & & $5 \cdot 2$ & & $5 \cdot 1$ \\
\hline \multicolumn{5}{|c|}{ Age of the newborn at baseline (months) } \\
\hline Mean & & 3.7 & & \\
\hline SD & & $1 \cdot 2$ & & \\
\hline \multicolumn{5}{|c|}{ Duration of pregnancy (weeks) } \\
\hline Mean & & $38 \cdot 8$ & & \\
\hline SD & & $2 \cdot 4$ & & \\
\hline \multicolumn{5}{|c|}{ Currently breast-feeding the baby } \\
\hline Yes & $72 \cdot 7$ & $67 \cdot 6,77 \cdot 9$ & & \\
\hline No & $27 \cdot 3$ & $22 \cdot 1,32 \cdot 4$ & & \\
\hline \multicolumn{5}{|l|}{ Education level } \\
\hline Low & $19 \cdot 2$ & $14 \cdot 9,23 \cdot 4$ & $26 \cdot 7$ & $21 \cdot 7,31 \cdot 7$ \\
\hline Intermediate & $25 \cdot 3$ & $20 \cdot 7,30 \cdot 0$ & $33 \cdot 1$ & $28 \cdot 8,37.4$ \\
\hline High & 55.5 & $49 \cdot 1,61 \cdot 9$ & $40 \cdot 2$ & $33.5,46.9$ \\
\hline \multicolumn{5}{|l|}{ Employment status } \\
\hline $\begin{array}{l}\text { On maternity/paternity } \\
\text { leave or home duties } \\
\text { full time }\end{array}$ & $84 \cdot 1$ & $80 \cdot 4,87 \cdot 8$ & & 0 \\
\hline Employed & $8 \cdot 4$ & $5 \cdot 7,11 \cdot 1$ & $97 \cdot 3$ & $95 \cdot 8,98 \cdot 9$ \\
\hline $\begin{array}{l}\text { Unemployed, student } \\
\text { or other }\end{array}$ & $7 \cdot 5$ & $4 \cdot 9,10 \cdot 1$ & $2 \cdot 7$ & $1 \cdot 1,4 \cdot 2$ \\
\hline \multicolumn{5}{|l|}{ Country of birth } \\
\hline Australia & $78 \cdot 9$ & $74 \cdot 5,83 \cdot 2$ & $77 \cdot 2$ & $73.5,80 \cdot 9$ \\
\hline Other & $21 \cdot 1$ & $16 \cdot 8,25 \cdot 5$ & $22 \cdot 8$ & $19 \cdot 3,26 \cdot 5$ \\
\hline \multicolumn{5}{|l|}{ Language spoken at home } \\
\hline English & $94 \cdot 3$ & $91 \cdot 6,97 \cdot 0$ & $95 \cdot 6$ & $93 \cdot 3,97 \cdot 8$ \\
\hline Other & $5 \cdot 7$ & $3.0,8.4$ & $4 \cdot 4$ & $2 \cdot 2,6 \cdot 7$ \\
\hline
\end{tabular}

confectionery other than chocolate-based). This pattern was labelled 'Cereals and sweet foods'. It is noteworthy that similar results were observed when we included fifty-four first-time mothers who completed their FFQ but whose partner had not (data not shown).

In fathers, four dietary patterns were also identified, accounting for $23.5 \%$ of the explained variance (Table 2). The first pattern, labelled 'Fruits', was characterised by high consumption of wholemeal crackers, fruits, non-fried fish, ricotta and cottage cheese, as well as two non-core foods (salty biscuits and confectioneries). The second pattern had high loadings for potatoes and vegetables, and was thus labelled 'Potatoes and vegetables'. The third pattern, 'Highfat foods', was characterised by high consumption of white bread, red meats, sausages, fried fish, pizzas, butter added to vegetables and low consumption of non-white bread and breakfast cereals. The fourth pattern was mainly characterised by potatoes (both with no added and added fat), cheese, savoury pastries, crisps, sweet biscuits, cakes and pastries, ice cream, chocolate-based products, and ketchup. This pattern was labelled 'High-energy snack and processed foods'. 
Nes British Journal of Nutrition

Table 2. Factor loadings for the rotated patterns in mothers and fathers

\begin{tabular}{|c|c|c|c|c|c|c|c|c|}
\hline \multirow[b]{3}{*}{ Labels } & \multicolumn{4}{|c|}{ Mothers ( $n$ 454) } & \multicolumn{4}{|c|}{ Fathers ( $n$ 454) } \\
\hline & Pattern 1 & Pattern 2 & Pattern 3 & Pattern 4 & Pattern 1 & Pattern 2 & Pattern 3 & Pattern 4 \\
\hline & $\begin{array}{l}\text { Fruits and } \\
\text { vegetables }\end{array}$ & $\begin{array}{l}\text { High-energy snack } \\
\text { and processed foods }\end{array}$ & $\begin{array}{l}\text { High-fat } \\
\text { foods }\end{array}$ & $\begin{array}{l}\text { Cereals and } \\
\text { sweet foods }\end{array}$ & Fruits & $\begin{array}{c}\text { Potatoes and } \\
\text { vegetables }\end{array}$ & $\begin{array}{l}\text { High-fat } \\
\text { foods }\end{array}$ & $\begin{array}{l}\text { High-energy snack } \\
\text { and processed foods }\end{array}$ \\
\hline \multicolumn{9}{|l|}{ Food groups } \\
\hline Full-cream milk & 0.06 & -0.02 & $0.21^{*}$ & $-0.26^{*}$ & -0.01 & 0.01 & 0.13 & 0.01 \\
\hline Reduced-fat milk & -0.11 & 0.07 & -0.20 & $0.28^{*}$ & 0.07 & 0.02 & -0.18 & 0.05 \\
\hline Other milks: soya milk or others & $0 \cdot 16$ & 0.01 & -0.07 & -0.07 & 0.09 & -0.02 & -0.13 & 0.01 \\
\hline Diet carbonated soft drinks & $-0.21^{*}$ & 0.05 & 0.02 & 0.19 & -0.08 & -0.03 & 0.01 & 0.16 \\
\hline Non-diet carbonated soft drinks & -0.10 & 0.03 & 0.16 & -0.02 & -0.08 & -0.10 & 0.14 & 0.09 \\
\hline Fruit juices & -0.02 & 0.03 & 0.16 & 0.02 & 0.10 & 0 & 0.07 & $0 \cdot 10$ \\
\hline White bread & $-0 \cdot 10$ & 0.04 & $0.25^{*}$ & $-0 \cdot 10$ & -0.07 & -0.06 & $0.27^{*}$ & 0.05 \\
\hline Non-white bread $\ddagger$ & 0.09 & 0.08 & -0.13 & 0.14 & 0.07 & 0.10 & $-0.23^{\star}$ & 0.17 \\
\hline Wholemeal crackers & 0.04 & -0.05 & 0.01 & $0.47^{*}$ & $0.33^{*}$ & -0.05 & -0.03 & 0.04 \\
\hline Porridge & 0.18 & -0.03 & -0.07 & -0.12 & 0.14 & 0.07 & 0.14 & -0.14 \\
\hline Breakfast cereals & -0.05 & 0.07 & $-0 \cdot 11$ & $0.24^{*}$ & 0.18 & -0.02 & $-0.23^{*}$ & 0.08 \\
\hline Rice & 0.09 & -0.15 & 0.19 & -0.02 & 0.04 & 0.04 & 0.08 & -0.13 \\
\hline Pasta & 0.08 & 0.01 & 0.13 & 0.02 & 0.05 & 0 & 0.18 & -0.11 \\
\hline Non-fat potatoes & $-0 \cdot 11$ & 0.06 & 0 & 0.06 & -0.07 & $0.29^{*}$ & -0.02 & $0.20^{*}$ \\
\hline Raw vegetables & $0.31^{*}$ & 0 & 0.06 & 0.13 & 0.05 & $0.45^{*}$ & 0 & -0.03 \\
\hline Cooked vegetables & $0.26^{*}$ & -0.05 & 0.07 & 0.09 & 0.01 & $0.48^{*}$ & 0 & 0.03 \\
\hline Legumes & $0.28^{*}$ & -0.08 & 0 & 0.03 & -0.03 & $0.42^{*}$ & -0.01 & -0.07 \\
\hline Common fresh fruits§ & $0.23^{*}$ & -0.01 & -0.06 & 0.11 & $0.27^{\star}$ & 0.12 & -0.09 & 0 \\
\hline Other fresh fruits & $0.23^{*}$ & 0 & 0.02 & 0.02 & $0.29^{*}$ & 0.06 & 0.08 & -0.09 \\
\hline Tinned or dried fruits & 0.14 & 0.02 & 0.09 & 0.11 & $0.25^{\star}$ & 0.09 & 0.04 & -0.02 \\
\hline Ricotta and cottage cheese & 0.10 & -0.05 & 0.10 & 0.07 & $0.20^{*}$ & 0 & 0.10 & -0.13 \\
\hline All other cheeses & 0.11 & 0.18 & 0.06 & $0 \cdot 10$ & $0 \cdot 10$ & 0.05 & 0 & $0.22^{*}$ \\
\hline Yogurt & $0 \cdot 19$ & 0.02 & -0.02 & 0.15 & 0.17 & 0.01 & -0.19 & 0.08 \\
\hline Eggs & 0.15 & -0.02 & 0.12 & 0 & 0.01 & 0.10 & 0.04 & 0.09 \\
\hline Chicken & -0.13 & -0.02 & 0.12 & 0.09 & -0.04 & 0.07 & 0.11 & 0.14 \\
\hline Red meats $\|$ & -0.02 & -0.02 & $0 \cdot 16$ & 0.05 & 0.05 & 0.03 & $0.29^{*}$ & 0.07 \\
\hline Sausages & -0.07 & 0.04 & 0.18 & 0.07 & 0 & 0.03 & $0.34^{*}$ & 0.07 \\
\hline Deli meats & -0.08 & 0.13 & 0.15 & 0.09 & -0.03 & 0.05 & 0.10 & $0.26^{*}$ \\
\hline Non-fried fish & $0.25^{*}$ & -0.04 & -0.03 & 0.03 & $0.21^{*}$ & 0.05 & 0.03 & -0.03 \\
\hline Fried fish & 0.09 & -0.03 & $0.24^{*}$ & -0.03 & 0.06 & 0.03 & $0.35^{\star}$ & -0.03 \\
\hline Potatoes cooked in fat & -0.09 & 0.05 & $0.29^{*}$ & 0.02 & -0.13 & $0.24^{*}$ & $0 \cdot 16$ & $0.21^{*}$ \\
\hline Savoury pastries & -0.02 & $0.42^{*}$ & -0.01 & -0.04 & -0.04 & -0.02 & 0.17 & $0.20^{*}$ \\
\hline Pizzas & 0 & $0.43^{\star}$ & -0.07 & -0.06 & 0 & -0.04 & $0.27^{*}$ & 0.04 \\
\hline Salty and non-wholemeal biscuits & 0.02 & -0.03 & 0.17 & 0.14 & $0.21^{*}$ & -0.14 & 0.05 & 0.15 \\
\hline Crisps $^{\star *}$ & -0.03 & $0.32^{*}$ & 0.09 & 0.02 & -0.03 & -0.05 & 0 & $0.28^{*}$ \\
\hline Sweet biscuits & 0.02 & 0 & 0.18 & 0.06 & 0.15 & -0.13 & -0.02 & $0.23^{*}$ \\
\hline Cakes and pastries & 0.03 & 0.05 & $0.23^{*}$ & 0.01 & 0.17 & -0.16 & 0.08 & $0.20^{*}$ \\
\hline Ice cream & -0.14 & 0.04 & 0.15 & $0.21^{*}$ & 0.06 & -0.08 & -0.01 & $0.23^{*}$ \\
\hline Chocolate-based products $\dagger \dagger$ & -0.02 & $0.21^{*}$ & 0.15 & 0.03 & 0.06 & -0.05 & -0.04 & $0.28^{*}$ \\
\hline Other confectionery & 0.04 & -0.05 & 0.01 & $0.47^{\star}$ & $0.33^{*}$ & -0.05 & -0.03 & 0.04 \\
\hline Olives & 0.19 & $0.25^{*}$ & 0 & -0.04 & 0.15 & 0.07 & 0.05 & -0.08 \\
\hline 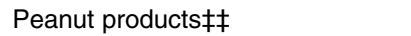 & 0.09 & $0.25^{*}$ & 0.02 & -0.02 & 0.07 & 0.01 & -0.01 & 0.18 \\
\hline Nuts other than peanuts & $0.24^{*}$ & 0.17 & -0.08 & -0.04 & 0.18 & $0 \cdot 10$ & $-0 \cdot 11$ & -0.02 \\
\hline Tomato sauce or ketchup & -0.09 & $0.30^{*}$ & 0.10 & 0 & -0.12 & 0.06 & 0.02 & $0.28^{*}$ \\
\hline Fat spreads§§ & 0.03 & 0.10 & $0.23^{*}$ & 0.03 & 0.09 & 0.09 & 0.09 & 0.15 \\
\hline Oil and vinegar salad dressing & $0.20^{*}$ & 0.03 & 0.12 & 0.01 & $0 \cdot 16$ & 0.05 & 0.17 & -0.18 \\
\hline Low-energy salad dressing & 0.01 & -0.05 & 0.09 & 0.16 & 0.14 & 0.04 & 0.09 & -0.01 \\
\hline Butter on vegetables & 0.02 & -0.05 & $0.27^{\star}$ & -0.08 & 0.11 & -0.05 & $0 \cdot 20^{\star}$ & 0.01 \\
\hline Margarine or oil on vegetables & 0.05 & -0.12 & $0.26^{*}$ & 0 & 0.17 & -0.06 & 0.13 & -0.03 \\
\hline
\end{tabular}




\section{Associations with age and education level}

Age was positively associated with dietary patterns characterised by high consumption of fruits and non-fried fish, namely 'Fruits and vegetables' in mothers $(P<0.001)$ and 'Fruits' in fathers $(P=0.005$; Table 3$)$. In contrast, age was inversely associated with the fathers' scores for the 'High-fat foods' pattern $(P=0.03)$. Higher means in three prudent pattern scores (i.e. 'Fruits and vegetables' $(P<0 \cdot 001)$, 'Cereals and sweet foods' $\left(P_{\text {trend }}=0.002\right)$ in mothers; 'Fruits' $\left(P_{\text {trend }}=0.03\right)$ in fathers) were observed with increasing education levels. However, the 'High-fat foods' pattern in both mothers $\left(P_{\text {trend }}=0.05\right)$ and fathers $\left(P_{\text {trend }}=0.008\right)$ was inversely associated with education level. The 'High-energy snack and processed foods' pattern was inversely correlated with education level in fathers only $\left(P_{\text {trend }}=0.001\right)$.

\section{Correlations between mothers and fathers}

Qualitatively similar patterns for mothers and fathers were the most strongly correlated ( $\rho$ ranging from 0.34 to 0.45 , $P<0.001$ ), namely 'Fruits and vegetables' in mothers with both 'Fruits' and 'Potatoes and vegetables' in fathers; 'Highfat foods' in mothers and fathers; and 'High-energy snack and processed foods' in mothers and fathers (Table 4). These results were confirmed by relatively high percentages of agreement regarding the third tertiles of mothers' and fathers' pattern scores, that is: $54.3 \%$ with the 'Fruits and vegetables' and 'Fruits' dietary patterns; $47.7 \%$ with the 'Fruits and vegetables' and 'Potatoes and vegetables' dietary patterns; 45.7\% with the 'High-energy snack and processed foods' pattern; and $49 \%$ with the 'High-fat' pattern (data not shown).

The 'High-fat foods' and 'High-energy snack and processed foods' patterns were also significantly correlated between mothers and fathers, but to a lesser extent $(\rho=0 \cdot 19$ and $\rho=0 \cdot 21)$. Finally, the pattern labelled 'Cereals and sweet foods' in mothers was positively correlated with the 'Fruits' pattern in fathers $(\rho=0 \cdot 18)$, and inversely correlated with the 'High-fat foods' pattern in fathers $(\rho=-0 \cdot 19)$. These correlations did not differ according to education level (data not shown).

\section{Discussion}

While some studies have examined dietary patterns in men and women generally, studies focusing on dietary intake of parents specifically are rare ${ }^{(15)}$. To our knowledge, the present study is the first to have explored dietary patterns in a large sample of first-time mothers and fathers in Australia. The present study has provided interesting insights into parents' dietary choices and the correlations between the mothers' and fathers' diets. These insights are important in informing appropriately targeted family-based interventions concerning the diet.

The present study identified four dietary patterns independently in mothers and fathers. We identified common traits between the present findings and a recent study involving Australian women aged 25-30 and 50-55 years ${ }^{(10)}$. 
That study used similar methodology (in terms of FFQ and analytical approaches), but a higher number of food groups were considered in that study (i.e. eighty-five), leading to dietary patterns with a higher level of detail regarding food items. Their first three patterns labelled 'Cooked vegetables', 'Fruit' and 'Mediterranean style' are similar to those summarised in the 'Fruits and vegetables' pattern derived for mothers in the present study. They identified two other patterns labelled 'Processed meat, meat and takeaway' and 'High-fat and sugar foods', while we derived similar patterns named 'Highfat foods' and 'High-energy snack and processed foods'.

Studies internationally have also shown some consistency with these findings. Knudsen et al. ${ }^{(22)}$ used factor analysis to define dietary patterns in Danish pregnant women and identified two major patterns: 'Western diet' and 'Health conscious'. In another study involving 6125 non-pregnant women aged 20-34 years from Southampton (UK) ${ }^{(23)}$, two main patterns were again derived: 'Prudent' and 'High-energy'. Although food groups which load high under a given label are not necessarily all the same from one study to another, overall, factor analyses undertaken in adults have often described the so-called 'Prudent' (or 'Healthy', 'Health conscious') pattern; the latter has been notably characterised by high consumption of fruit and vegetables, dairy, and fish ${ }^{(6)}$. The patterns identified in the present study, 'Fruits and vegetables' in mothers, and 'Fruits' and 'Potatoes and vegetables' in fathers, had similar characteristics to the 'Prudent' pattern. Conversely, patterns with high loadings for red and processed meats, refined grains, and processed foods have often been labelled as 'Western',(6), similar to the 'High-fat foods' and 'High-energy snack and processed foods' patterns identified in the present study in mothers and fathers.

Age has been shown to correlate positively with 'Prudent'like patterns ${ }^{(6)}$. Interestingly, this relationship was confirmed in the present dataset despite the narrow age range considered, indicating that these age trends are already set in early adulthood. The higher consumption of nutrient-dense and low-energy-dense foods among highly educated individuals and, conversely, the intake of nutrient-poor and energy-dense foods in the lowest socio-economic groups have previously been reported in other studies undertaken in industrialised countries ${ }^{(24)}$, including Australia ${ }^{(25,26)}$. The present study confirmed that the 'Prudent' pattern average scores were higher in the most educated backgrounds, as opposed to the 'Western' pattern scores. It has been suggested that level of education is likely to influence literacy, knowledge of nutrition, and health-related behaviour including diet $^{(27,28)}$. It is noteworthy that maternal nutrition knowledge has been found to partly mediate the association between educational achievement and maternal diet quality, in another study based on the same dataset ${ }^{(17)}$.

As noted by Northstone \& Emmett ${ }^{(15)}$, most studies using exploratory analyses have derived patterns for men and women combined. However, observed differences in pattern scores by sex are controversial ${ }^{(6)}$ and may depend on the age range considered, the origin of the population studied and methodological issues. Deriving patterns independently in men and women, and more specifically in fathers and mothers, is likely to lead to more nuanced results. This has been confirmed in the findings of a study in young mothers ${ }^{(9)}$ and fathers ${ }^{(15)}$, which revealed similar but not identical dietary patterns between sexes. In the present study, three qualitatively similar patterns were observed in mothers and fathers: 'Fruits and vegetables'; 'High-fat foods'; 'High-energy snack and processed foods'. However, while, for example, the 'Healthy' pattern included fruits and vegetables in mothers, it did not include vegetables but included non-core foods in fathers. In addition, the 'High-energy snack and processed foods' pattern was characterised more by savoury snacks in mothers than in fathers. The following two other patterns were more sex-specific: 'Cereals and sweet foods' in mothers and 'Potatoes and vegetables' in fathers. Interestingly, Northstone \& Emmett ${ }^{(15)}$ also observed in men that vegetables and potatoes did not load strongly in their pattern called 'Health conscious'. Instead, these groups were strongly correlated with a specific pattern observed in men only, which was labelled 'Traditional'. Therefore, while women's consumption of fruits and vegetables are related, the fact that they remain independent in men suggests that health promotion messages would need to target both fruits and vegetables independently. Despite these sex specificities, qualitatively similar patterns in mothers and fathers were the most strongly correlated, as also observed in the study by Northstone \& Emmett ${ }^{(15)}$. Increasing our understanding of the foods that characterise the eating patterns of mothers and fathers independently, along with the information on how these various patterns correlate within households, provides complementary indications to refine the development and implementation of familybased interventions.

Studies that have investigated and reported positive relationships between fathers' and children's diets ${ }^{(29-31)}$ are uncommon. There is, however, clearer evidence that children's eating patterns are influenced by their mothers' $\operatorname{diet}^{(32-38)}$. This influence is likely to be exerted from very early ages, not only through modelling of eating behaviours but also through the foods available within the household ${ }^{(4,5)}$. It is possible that the influence on children's diets may be stronger if dietary patterns correlate between parents.

Some limitations of the study need to be acknowledged. First, although all levels of socio-economic position were represented in the present study, the sample is generally well educated, with $55.5 \%$ reporting high education level. In addition, participants in the present study were older than the average age of first-time mothers in Victoria (32.3 years compared with $29 \cdot 1$ years $)^{(39)}$. These characteristics may have implications for generalisability. However, they may be partially explained by the inclusion of only urban Melbourne residents in the trial, who are likely to differ from the broader Victorian population. A study of 1507 first-time mothers recruited during early pregnancy from metropolitan hospitals across Melbourne in 2003-2005 has provided a comparable urban sample ${ }^{(40)}$. In that study, $46 \%$ reported tertiary or higher education, and $57 \%$ were aged 30 years or older at childbirth (compared with 69\% in the Melbourne InFANT Program $)^{(41)}$. Second, we acknowledge that the estimation of food intake is more precise with a quantitative FFQ. However, 
Table 3. Dietary pattern scores in both mothers and fathers according to age and education level (Adjusted parameter estimates and $95 \%$ confidence intervals.)

\begin{tabular}{|c|c|c|c|c|c|c|c|c|}
\hline & \multicolumn{8}{|c|}{ Mothers ( $n$ 454) } \\
\hline & \multicolumn{2}{|c|}{ Pattern 1} & \multicolumn{2}{|c|}{ Pattern 2} & \multicolumn{2}{|c|}{ Pattern 3} & \multicolumn{2}{|c|}{ Pattern 4} \\
\hline & \multicolumn{2}{|c|}{ Fruits and vegetables } & \multicolumn{2}{|c|}{$\begin{array}{l}\text { High-energy snack and processed } \\
\text { foods }\end{array}$} & \multicolumn{2}{|c|}{ High-fat foods } & \multicolumn{2}{|c|}{ Cereals and sweet foods } \\
\hline & Adjusted parameter & $95 \% \mathrm{Cl}$ & Adjusted parameter & $95 \% \mathrm{Cl}$ & Adjusted paramete & $95 \% \mathrm{Cl}$ & Adjusted parameter & $95 \% \mathrm{Cl}$ \\
\hline $\begin{array}{l}\text { Age (continuous) } \\
P\end{array}$ & \multicolumn{2}{|c|}{ 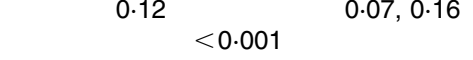 } & \multicolumn{2}{|r|}{$-0.03,0.07$} & \multicolumn{2}{|r|}{ - } & \multicolumn{2}{|r|}{ - } \\
\hline \multicolumn{9}{|l|}{ Education } \\
\hline Low & \multicolumn{2}{|c|}{ Reference } & \multicolumn{2}{|c|}{ Reference } & \multicolumn{2}{|c|}{ Reference } & \multicolumn{2}{|c|}{ Reference } \\
\hline Intermediate & -0.03 & $-0.44,0.39$ & -0.18 & $-0.58,0.23$ & -0.14 & $-0.68,0.40$ & 0.24 & $-0.16,0.65$ \\
\hline High & 0.73 & $0.35,1.11$ & 0.10 & $-0.33,0.53$ & -0.46 & $-1.01,0.08$ & 0.61 & $0.23,0.98$ \\
\hline$P$ & \multirow{2}{*}{\multicolumn{2}{|c|}{$\begin{array}{l}<0.001 \\
<0.001\end{array}$}} & \multirow{2}{*}{\multicolumn{2}{|c|}{$\begin{array}{l}0.28 \\
0.43\end{array}$}} & \multirow{2}{*}{\multicolumn{2}{|c|}{$\begin{array}{l}0.07 \\
0.05\end{array}$}} & \multirow{2}{*}{\multicolumn{2}{|c|}{$\begin{array}{l}0.008 \\
0.002\end{array}$}} \\
\hline \multirow[t]{5}{*}{$P_{\text {trend }}$} & & & & & & & & \\
\hline & \multicolumn{8}{|c|}{ Fathers ( $n$ 454) } \\
\hline & \multicolumn{2}{|c|}{ Pattern 1} & \multicolumn{2}{|c|}{ Pattern 2} & \multicolumn{2}{|c|}{ Pattern 3} & \multicolumn{2}{|c|}{ Pattern 4} \\
\hline & \multicolumn{2}{|c|}{ Fruits } & \multicolumn{2}{|c|}{ Potatoes and vegetables } & \multicolumn{2}{|c|}{ High-fat foods } & \multicolumn{2}{|c|}{$\begin{array}{l}\text { High-energy snack and processed } \\
\text { foods }\end{array}$} \\
\hline & Adjusted parameter & $95 \% \mathrm{Cl}$ & Adjusted parameter & $95 \% \mathrm{Cl}$ & Adjusted parameter & $95 \% \mathrm{Cl}$ & Adjusted parameter & $95 \% \mathrm{Cl}$ \\
\hline Age (continuous) & \multirow{2}{*}{\multicolumn{2}{|c|}{$0.02,0.09$}} & \multirow{2}{*}{\multicolumn{2}{|c|}{$0,0.05$}} & -0.04 & $-0.08,0$ & -0.02 & $-0.05,0.01$ \\
\hline $\begin{array}{l}P \\
\text { Education }\end{array}$ & & & & & 0.0 & & $0 \cdot 16$ & \\
\hline Low & Refere & & Referen & & Refere & & Referer & \\
\hline Intermediate & 0.29 & $-0.17,0.76$ & -0.04 & $-0.57,0.48$ & -0.33 & $-0.85,0.20$ & -0.16 & $-0.55,0.23$ \\
\hline High & 0.54 & $0.04,1.04$ & 0.21 & $-0.28,0.70$ & -0.58 & $-1.01,-0.14$ & -0.62 & $-1.00,-0.25$ \\
\hline$P$ & 0.11 & & 0.16 & & 0.0 & & 0.005 & \\
\hline$P_{\text {trend }}$ & 0.03 & & 0.31 & & 0.00 & & 0.001 & \\
\hline
\end{tabular}


Table 4. Spearman's correlation coefficients between mothers' and fathers' patterns ( $n 454$ pairs)

\begin{tabular}{|c|c|c|c|c|}
\hline & \multicolumn{4}{|c|}{ Fathers' patterns } \\
\hline & Fruits & $\begin{array}{l}\text { Potatoes and } \\
\text { vegetables }\end{array}$ & High-fat foods & $\begin{array}{l}\text { High-energy snack } \\
\text { and processed foods }\end{array}$ \\
\hline \multicolumn{5}{|l|}{ Mothers' patterns } \\
\hline Fruits and vegetables & $0.42^{\star \star \star}$ & $0 \cdot 37^{\star \star \star}$ & $-0 \cdot 14^{\star \star}$ & $-0 \cdot 19^{\star \star \star}$ \\
\hline High-energy snack and processed foods & -0.02 & 0.03 & $0 \cdot 21^{\star \star \star}$ & $0 \cdot 34^{\star \star \star}$ \\
\hline High-fat foods & -0.05 & -0.06 & $0.45^{\star \star \star}$ & $0 \cdot 19^{\star \star \star}$ \\
\hline Cereals and sweet foods & $0 \cdot 18^{\star \star *}$ & 0.07 & $-0 \cdot 19^{\star \star \star}$ & $0 \cdot 12^{\star \star}$ \\
\hline
\end{tabular}

${ }^{\star} P<0.05 ;{ }^{* *} P<0.01 ;{ }^{* \star} P<0.001$.

research has shown that frequency of consumption is actually the major determinant of intake, and the addition of portion or serve size to FFQ does not improve their ability to predict intake at a population level ${ }^{(42)}$. The use of frequencies of consumption is commonly used in the identification of dietary patterns by factor analysis or $\mathrm{PCA}^{(6)}$. We also acknowledge that the factor loadings reported in the present study are not as high as other previously reported studies ${ }^{(7-10,15,22)}$, which might have been a concern for interpretability of the patterns. However, our approach has been to consider the highest loading foods to describe the patterns (i.e. the ranking of foods in the pattern); as such, they were useful to differentiate the dietary patterns from each other. Overall, the present study involved PCA, which is an exploratory statistical alternative among the factor analyses' general methodology. Comparison with other findings is not straightforward due to the datadriven approach to pattern analysis, with different methodologies employed in the collection of dietary data, subjective redistribution of the former items (i.e. foods) into food groups, the transformation of these variables (e.g. standardisation), defining the number of groups for inclusion in factor analyses, the methods of rotation of components (if any) employed, and the number of patterns identified - all complicating the opportunities for comparison. Despite these potential variations in methodology, Newby \& Tucker $^{(6)}$ reported in their review that some reproducibility has been observed between most studies which have identified patterns in adults. This consistency over national and international studies was confirmed for the present study, as described previously.

These findings from the baseline data are all the more relevant in the context of the Melbourne InFANT Program, which focused on parenting skills and strategies aimed at promoting the development of healthy behaviours from early infancy, including eating. Deleterious food choices have been shown to correlate with sedentary behaviours, low physical activity and overweight not only in adults ${ }^{(6)}$ but also in children ${ }^{(43-45)}$. Moreover, diet-related behaviours established in early life have been shown to track throughout childhood $^{(46)}$, suggesting that the home environment influences on children tend to persist over time ${ }^{(47)}$. Behavioural trajectories are therefore likely to start at very young ages, along with a strong familial component. Identifying first-time parents with unhealthy dietary patterns is likely to be an effective strategy in targeting child obesity prevention.

\section{Acknowledgements}

This study was funded by an Australian National Health and Medical Research Council Project Grant (no. 425801). S. L. was supported by an Alfred Deakin Postdoctoral Fellowship (Deakin University). S. A. M. was supported by a National Heart Foundation of Australia Postdoctoral Fellowship. A. C. S was supported by a Deakin University Postgraduate Research Scholarship. D. C. and K. J. C. were supported by fellowships from the Victorian Health Promotion Foundation. K. H. was supported by a National Heart Foundation of Australia Career Development Award. The authors' contributions were as follows: S. L. conducted the statistical analysis, contributed to the interpretation of the results, drafted and edited the manuscript, and had primary responsibility for the final content. S. A. M. conducted the dietary data collection, guided the statistical analysis, contributed to the interpretation of the results, drafted and edited the manuscript. D. C. guided the statistical analysis, contributed to the interpretation of the results, drafted and edited the manuscript. A. C. S conducted the dietary data collection, drafted and edited the manuscript. K. H. designed and led the Melbourne InFANT Program, guided the statistical analysis, contributed to the interpretation of the results, drafted and edited the manuscript. K. J. C. was the principal investigator on the Melbourne InFANT Program. She designed and led that study, conducted the dietary data collection, guided the statistical analysis, contributed to the interpretation of the results, drafted and edited the manuscript. All authors read and approved the final manuscript. None of the authors had a conflict of interest.

\section{References}

1. Davison KK \& Birch LL (2001) Childhood overweight: a contextual model and recommendations for future research. Obes Rev 2, 159-171.

2. van der Horst K, Oenema A, Ferreira I, et al. (2007) A systematic review of environmental correlates of obesity-related dietary behaviors in youth. Health Educ Res 22, 203-226.

3. Pearson N, Biddle SJ \& Gorely T (2009) Family correlates of fruit and vegetable consumption in children and adolescents: a systematic review. Public Health Nutr 12, 267-283.

4. Hannon PA, Bowen DJ, Moinpour CM, et al. (2003) Correlations in perceived food use between the family food preparer and their spouses and children. Appetite 40, 77-83.

5. Scaglioni S, Salvioni M \& Galimberti C (2008) Influence of parental attitudes in the development of children eating behaviour. Br J Nutr 99, Suppl. 1, S22-S25. 
6. Newby PK \& Tucker KL (2004) Empirically derived eating patterns using factor or cluster analysis: a review. Nutr Rev 62, 177-203.

7. Newby PK, Weismayer C, Akesson A, et al. (2006) Long-term stability of food patterns identified by use of factor analysis among Swedish women. J Nutr 136, 626-633.

8. Touvier M, Niravong M, Volatier JL, et al. (2009) Dietary patterns associated with vitamin/mineral supplement use and smoking among women of the E3N-EPIC cohort. Eur J Clin Nutr 63, 39-47.

9. Northstone K, Emmett P \& Rogers I (2008) Dietary patterns in pregnancy and associations with socio-demographic and lifestyle factors. Eur J Clin Nutr 62, 471-479.

10. Mishra G, McNaughton SA, BAll K, et al. (2010) Major dietary patterns of young and middle aged women: results from a prospective Australian cohort study. Eur J Epidemiol 64, 1125-1133.

11. Mishra G, Ball K, Arbuckle J, et al. (2002) Dietary patterns of Australian adults and their association with socioeconomic status: results from the 1995 National Nutrition Survey. Eur J Clin Nutr 56, 687-693.

12. McNaughton SA, Mishra GD, Bramwell G, et al. (2005) Comparability of dietary patterns assessed by multiple dietary assessment methods: results from the 1946 British Birth Cohort. Eur J Clin Nutr 59, 341-352.

13. Hure A, Young A, Smith R, et al. (2009) Diet and pregnancy status in Australian women. Public Health Nutr 12, 853-861.

14. Schafer RB, Schafer E, Dunbar M, et al. (1999) Marital food interaction and dietary behavior. Soc Sci Med 48, 787-796.

15. Northstone K \& Emmett PM (2010) Dietary patterns of men in ALSPAC: associations with socio-demographic and lifestyle characteristics, nutrient intake and comparison with women's dietary patterns. Eur J Clin Nutr 64, 978-986.

16. Campbell K, Hesketh K, Crawford D, et al. (2008) The Infant Feeding Activity and Nutrition Trial (INFANT) an early intervention to prevent childhood obesity: cluster-randomised controlled trial. BMC Public Health 8, 103.

17. McLeod ER, Campbell KJ \& Hesketh KD (2011) Nutrition knowledge: a mediator between socioeconomic position and diet quality in Australian first-time mothers. J Am Diet Assoc 111, 696-704.

18. Ireland P, Jolley D \& Giles G (1994) Development of the Melbourne FFQ: a food frequency questionnaire for use in an Australian prospective study involving an ethnically diverse cohort. Asia Pacific J Clin Nutr 19, 19-31.

19. Willett W (1998) Nutritional Epidemiology. New York, NY: Oxford University Press.

20. Kline P (1994) An Easy Guide to Factor Analysis. London: Routledge.

21. Cattell RB (1966) The scree test for the number of factors. Multivariate Behav Res 1, 245-276.

22. Knudsen VK, Orozova-Bekkevold IM, Mikkelsen TB, et al. (2008) Major dietary patterns in pregnancy and fetal growth. Eur J Clin Nutr 62, 463-470.

23. Crozier SR, Robinson SM, Borland SE, et al. (2006) Dietary patterns in the Southampton Women's Survey. Eur J Clin Nutr 60, 1391-1399.

24. Darmon N \& Drewnowski A (2008) Does social class predict diet quality? Am J Clin Nutr 87, 1107-1117.

25. Ball K, Mishra GD, Thane CW, et al. (2004) How well do Australian women comply with dietary guidelines? Public Health Nutr 7, 443-452.

26. Inglis V, Ball K \& Crawford D (2008) Socioeconomic variations in women's diets: what is the role of perceptions of the local food environment? J Epidemiol Community Health 62, 191-197.
27. Sobal J (1991) Obesity and socioeconomic status: a framework for examining relationships between physical and social variables. Med Anthropol 13, 231-247.

28. Wardle J, Parmenter K \& Waller J (2000) Nutrition knowledge and food intake. Appetite 34, 269-275.

29. Oliveria SA, Ellison RC, Moore LL, et al. (1992) Parent-child relationships in nutrient intake: the Framingham Children's Study. Am J Clin Nutr 56, 593-598.

30. Hall L \& Collins C (2010) Relationship between father and child intakes of fruit, vegetables and non-core - the Healthy Dads Healthy Kids study. Nutr and Diet 67, 22-68.

31. Thorsdottir I, Gunnarsdottir I, Ingolfsdottir E, et al. (2006) Fruit and vegetable intake: vitamin $C$ and $\beta$-carotene intake and serum concentrations in six-year-old children and their parents. Scand J Food Nutr 50, 71-76.

32. Cooke LJ, Wardle J, Gibson EL, et al. (2004) Demographic, familial and trait predictors of fruit and vegetable consumption by pre-school children. Public Health Nutr 7, 295-302.

33. Vereecken CA, Keukelier E \& Maes L (2004) Influence of mother's educational level on food parenting practices and food habits of young children. Appetite 43, 93-103.

34. Wardle J, Carnell S \& Cooke L (2005) Parental control over feeding and children's fruit and vegetable intake: how are they related? J Am Diet Assoc 105, 227-232.

35. Robinson S, Marriott L, Poole J, et al. (2007) Dietary patterns in infancy: the importance of maternal and family influences on feeding practice. Br J Nutr 98, 1029-1037.

36. Brekke HK, van Odijk J \& Ludvigsson J (2007) Predictors and dietary consequences of frequent intake of high-sugar, lownutrient foods in 1-year-old children participating in the ABIS study. Br J Nutr 97, 176-181.

37. Ovaskainen ML, Nevalainen J, Uusitalo L, et al. (2009) Some similarities in dietary clusters of pre-school children and their mothers. Br J Nutr 102, 443-452.

38. Cameron AJ, Crawford DA, Salmon J, et al. (2011) Clustering of obesity-related risk behaviors in children and their mothers. Ann Epidemiol 21, 95-102.

39. Consultative Council on Obstetric and Paediatric Mortality and Morbidity (2008) Births in Victoria 2005 and 2006. Melbourne: Victorian Department of Human Services.

40. Brown SJ, Lumley JM, McDonald EA, et al. (2006) Maternal health study: a prospective cohort study of nulliparous women recruited in early pregnancy. BMC Pregnancy Childbirth 6, 12.

41. Woolhouse H, Brown S, Krastev A, et al. (2009) Seeking help for anxiety and depression after childbirth: results of the Maternal Health Study. Arch Womens Ment Health 12, 75-83.

42. Noethlings U, Hoffmann K, Bergmann MM, et al. (2003) Portion size adds limited information on variance in food intake of participants in the EPIC-Potsdam study. J Nutr 133, 510-515.

43. Northstone K \& Emmett P (2005) Multivariate analysis of diet in children at four and seven years of age and associations with socio-demographic characteristics. EurJ Clin Nutr 59, 751-760.

44. Aranceta J, Perez-Rodrigo C, Ribas L, et al. (2003) Sociodemographic and lifestyle determinants of food patterns in Spanish children and adolescents: the enKid study. Eur $J$ Clin Nutr 57, Suppl. 1, S40-S44.

45. Lioret S, Touvier M, Lafay L, et al. (2008) Dietary and physical activity patterns in French children are related to overweight and socioeconomic status. J Nutr 138, 101-107.

46. Northstone K \& Emmett PM (2008) Are dietary patterns stable throughout early and mid-childhood? A birth cohort study. Br J Nutr 100, 1069-1076.

47. Ashcroft J, Semmler C, Carnell S, et al. (2008) Continuity and stability of eating behaviour traits in children. Eur J Clin Nutr 62, 985-990. 